\title{
Rhizobium leguminosarum contains a group of genes that appear to code for methyl-accepting chemotaxis proteins
}

\author{
Christopher K. Yost, Patrice Rochepeau and Michael F. Hynes
}

Department of Biological Sciences, The University of Calgary, Calgary, Alberta, Canada T2N 1N4

\author{
Author for correspondence: Michael F. Hynes. Tel: +1 4032207136. Fax: +1 4032899311. \\ e-mail: hynes@acs.ucalgary.ca
}

\begin{abstract}
Methyl-accepting chemotaxis proteins (MCPs) play important roles in the chemotactic response of many bacteria. Oligonucleotide primers designed to amplify the conserved signalling domain of MCPs by PCR were used to identify potential MCP-encoding genes in Rhizobium leguminosarum. Using a PCRderived probe created from these primers a genomic library of $R$. leguminosarum VF39SM was screened; at least five putative MCP-encoding genes (termed $m c p B$ to $m c p F$ ) were identified and isolated from the library. One of these putative genes (mcpC) is located on one of the indigenous plasmids of VF39SM. Fifteen different cosmids showing homology to an mcpD probe were also isolated from a genomic library. The complete DNA sequences of $m c p B, m c p C$ and $m c p D$ were obtained. All three genes code for proteins with characteristics typical of MCPs. However, the protein encoded by mcpB has a relatively large periplasmic domain compared to that in other MCPs. Partial DNA sequences of mcpE and mcpF had strong similarity to sequences from the methylation domains of known MCPs. Mutants defective in mcpB, mcpC, mcpD or mcpE were created using insertional mutagenesis strategies. Mutation of $\mathbf{m c p B}$ resulted in impairment of chemotaxis to a wide range of carbon sources on swarm plates; phenotypes for the other three mutants have yet to be elucidated. The mcpB, mcpC and mcpD mutants were tested for loss of nodulation competitiveness. When co-inoculated with the wild-type, the mcpB and mcpC mutants formed fewer nodules than the wild-type, whereas the mcpD mutant was just as competitive as the wild-type. The results overall suggest that $R$. leguminosarum possesses mcp-like genes, and that at least some of these play a role in early steps in the plant-microbe interaction.
\end{abstract}

Keywords: rhizobia, chemotaxis, sensory proteins

\section{INTRODUCTION}

The study of bacterial chemotaxis has provided substantial information about the molecular mechanisms by which bacteria process and react to environmental information. Most of the knowledge of chemotaxis comes from research using enteric organisms such as Escherichia coli and Salmonella typhimurium. In these bacteria, many of the chemotaxis genes are contained

Abbreviations: DIG, digoxigenin; MCP, methyl-accepting chemotaxis protein.

The GenBank/EMBLDDBJ accession numbers for the sequences reported in this paper are: $m \subset \mathrm{CDB}$, AF022807; $m c p C$, AF036168; $m c p D$, U81828. within a single operon (cheA, cheY, cheW, cheR, cheB) (for reviews see Stock et al., 1991; Manson, 1992). Proteins CheA and CheY belong to a two-component regulatory system that modulates direction of flagellar rotation and thus determines the behaviour of the bacterium (reviewed by Matsumura et al., 1990; Parkinson, 1993). Methyl-accepting chemotaxis proteins (MCPs) may also play a role in this signalling pathway by serving as environmental sensors. They are transmembrane proteins with the carboxyl-terminus located in the cytoplasm and the amino-terminus exposed to the external environment (Boyd et al., 1983; Hazelbauer et al., 1990). The amino-terminal domain detects attractants and repellents, and the carboxyl-terminal domain relays this information to CheA, allowing the 
bacterium to swim towards attractants and away from repellents (Hazelbauer et al., 1990). Sensory adaptation occurs through methylation and demethylation of glutamate residues contained in the carboxyl-terminus of the protein (Hazelbauer, 1988). Generally, the binding of attractants leads to increased methylation of the MCP. Conservation of MCP amino acid sequences among bacteria occurs predominantly in the carboxyl-terminal region, where the MCP interacts with the signalling components $\mathrm{CheW}$ and CheA and where methylation occurs. A surge of interest in the chemotactic behaviour of other bacterial species has demonstrated that the chemotactic signalling pathway is highly conserved. Elements of the signalling pathway including cheA, cheY, cheW, cheR, cheB and MCP homologues have been found in a wide range of bacteria, such as Bacillus subtilis (Hanlon \& Ordal, 1994; Zuberi et al., 1990), Caulobacter crescentus (Alley et al., 1992), Myxococcus xanthus (McCleary et al., 1990; McCleary \& Zusman, 1990), and the archaeon Halobacterium halobium (Alam et al., 1989).

It has frequently been suggested that chemotaxis and motility must play an important role in the interaction of root-nodule-forming bacteria (collectively known as rhizobia) with their legume hosts (Currier \& Strobel, 1977; Ames \& Bergman, 1981; Gulash et al., 1984; Caetano-Anollés et al., 1988, 1992; Munoz Aguilar et al., 1988; Bauer \& Caetano-Anollés, 1990; Dharmatilake \& Bauer, 1992; reviewed by Bauer, 1991, and Vande Broek \& Vanderleyden, 1995). To confirm this hypothesis more information is needed about the chemotactic signalling pathways in rhizobia. Quite recently, Greck et al. (1995) have shown that Sinorhizobium meliloti contains a chemotaxis operon homologous to the $E$. coli chemotaxis operon. Genes identified using sequence homology to $E$. coli genes include che $A$, cheR, cheB, two cheY genes and two ORFs. The products of the two ORFs show amino acid similarity to the signalling domain of MCPs, but their predicted amino acid sequence lacks the other functional domains, such as transmembrane regions and the two methylation domains, characteristic of MCPs. The roles of the two ORFs in chemotaxis remain unclear. Previously, conflicting reports of in vivo methylation studies questioned the existence of MCP-encoding genes in Sinorbizobium and Rhizobium. Robinson \& Bauer (1993) observed no increase or decrease in protein methylation after Sinorhizobium meliloti cells were incubated with attractants such as L-amino acids or Dmannitol. However, Armitage et al. (1988) demonstrated an increase in protein methylation after Rhizobium leguminosarum cells were incubated with the chemoattractant L-serine. The latter experiment was in agreement with a study conducted by Morgan et al. (1993). Probing an S. meliloti Western blot with an antibody directed against an E. coli MCP (Trg) gave three hybridizing bands: a doublet between 65 and $70 \mathrm{kDa}$, and a band at $80 \mathrm{kDa}$. This provided further evidence that MCPs might exist in the rhizobia. When this research was initiated, the existence of MCP- encoding genes in Rhizobium had not been clearly established. More recently, genes with homology to MCPs have been found on plasmids in a strain of $R$. leguminosarum (Brito et al., 1996) and Rhizobium sp. NGR234 (Freiberg et al., 1997); however, no role in chemotaxis has been shown. This paper documents research conducted to identify and isolate $\mathrm{MCP}$ encoding genes from $R$. leguminosarum bv. viciae strain VF39SM.

\section{METHODS}

Bacterial strains, plasmids, and media. The bacterial strains and plasmids used are listed in Table $1 . R$. leguminosarum strains were grown on TY medium (Beringer, 1974) at $30^{\circ} \mathrm{C}$. E. coli strains were grown on LB medium (Sambrook et al., 1989) at $37^{\circ} \mathrm{C}$. Swarm medium was composed of $0.01 \%$ yeast extract, $1 \mathrm{mM} \mathrm{MgSO}$ and $0.3 \%$ (w/v) agar. The chemotactic response of $R$. leguminosarum to specific carbon sources was assayed using swarm plates containing Vincent's minimal medium (VMM; Vincent, 1970) with 0.15\% agarose and the potential chemoattractant as the sole carbon source $1 \mathrm{mM}$ final concentration). Carbon sources were purchased from Sigma-Aldrich. When necessary, Rbizobium strains were cultured in media containing antibiotics at the following concentrations : neomycin, $100 \mu \mathrm{g} \mathrm{ml}^{-1}$; spectinomycin, $500 \mu \mathrm{g}$ $\mathrm{ml}^{-1}$; tetracycline, $5 \mu \mathrm{g} \mathrm{ml}^{-1}$; streptomycin, $500 \mu \mathrm{g} \mathrm{ml}^{-1}$; and gentamicin, $30 \mu \mathrm{g} \mathrm{ml}^{-1}$. Antibiotic concentrations used when culturing $E$. coli strains were as follows: kanamycin, $50 \mu \mathrm{g}$ $\mathrm{ml}^{-1}$; tetracycline, $10 \mu \mathrm{g} \mathrm{ml}^{-1}$; streptomycin, $500 \mu \mathrm{g} \mathrm{ml}^{-1}$; gentamicin, $15 \mu \mathrm{g} \mathrm{ml}^{-1}$, and spectinomycin $100 \mu \mathrm{g} \mathrm{ml}^{-1}$.

Recombinant DNA techniques. All restriction endonucleases and modifying enzymes were purchased from Gibco-BRL, and used according to the manufacturer's specifications. Southern blots were hybridized with non-radioactive DIG-labelled DNA probes using reagents and protocols obtained from Boehringer Mannheim. Hybridizations were performed overnight at $67^{\circ} \mathrm{C}$ followed by washes of $2 \times$ SSC, $0.1 \%$ SDS at room temperature, and $0.1 \times \mathrm{SSC}, 0.1 \%$ SDS at $67^{\circ} \mathrm{C}$. All washes were done in duplicate. Hybridization signals were detected via chemiluminescence using CSPD substrate and a protocol supplied by Boehringer Mannheim.

Visualization of Rhizobium plasmids. When necessary the plasmids of VF39SM were visualized on agarose gels using a modified Eckhardt technique (Eckhardt, 1978) described by Hynes et al. (1985), as modified by Hynes \& McGregor (1990).

DNA sequencing and analysis. DNA sequencing was performed using an Applied Biosystems automated sequencer operated by University Core DNA Services (University of Calgary). ExolII deletions were used to obtain the complete DNA sequences of $m c p B, m c p C$ and $m c p D$. Enzymes and protocols for the ExolII deletions were obtained from Pharmacia. Partial DNA sequences of $m c p E$ and $m c p F$ were obtained from subclones in pBSIISK $(+)$ using T7 and T3 primers. Sequence homology searches were performed using the BLAST sequence alignment program (Altschul et al., 1990).

Identification of MCP-encoding genes in $R$. leguminosarum VF39SM. Primers designed from the DNA sequence of $\operatorname{dcr} A$, an MCP-encoding gene from Desulfovibrio vulgaris (Dolla et al., 1992), were used to amplify VF39SM genomic DNA by 
Table 1. Bacterial strains and plasmids

\begin{tabular}{|c|c|c|}
\hline $\begin{array}{l}\text { Strain or } \\
\text { plasmid }\end{array}$ & Relevant characteristic $(\mathbf{s})^{*}$ & Source or reference \\
\hline \multicolumn{3}{|l|}{ E. coli } \\
\hline $\mathrm{DH} 5 \alpha$ & $\begin{array}{l}\text { endA1 hsdR17 supE44 thi-1 recA1 gyrA96 } \\
\text { relA1 } \triangle(\text { argFlacZYA) U169 } \phi \text { 80dlacZ } \triangle \text { M15 }\end{array}$ & Gibco-BRL \\
\hline S17-1 & $\mathrm{Sp}^{\mathrm{r}}$; RP4 tra region, mobilizer strain & Simon et al. (1983) \\
\hline \multicolumn{3}{|c|}{ R. leguminosarum } \\
\hline VF39SM & biovar viciae, $\mathrm{St}^{\mathrm{r}}$ & Priefer (1989) \\
\hline LRS39201 & VF39SM cured of pRleVF39b & Hynes \& McGregor (1990) \\
\hline LRS39301 & VF39SM cured of pRleVF39c & Hynes \& McGregor (1990) \\
\hline LRS39401 & VF39SM cured of pRleVF39d & Hynes \& McGregor (1990) \\
\hline LRS39501 & VF39SM cured of pRleVF39e & Hynes \& McGregor (1990) \\
\hline LRS39601 & VF39SM cured of pRleVF39f & Hynes \& McGregor (1990) \\
\hline VF-MCPB- & VF39SM, $m c p B:: \Omega T c ; \mathrm{Tc}^{\mathrm{r}}$ & This work \\
\hline VF-MCPC- & VF39SM, $m c p C:: \Omega S p ; \mathrm{Sp}^{\mathrm{r}}$ & This work \\
\hline VF-MCPD ${ }^{-}$ & VF39SM, $m c p D:: \Omega \mathrm{Nm} ; \mathrm{Nm}^{\mathrm{r}}$ & This work \\
\hline VF-MCPE ${ }^{-}$ & VF39SM, $m c p E:: \Omega S p ; \mathrm{Sp}^{r}$ & This work \\
\hline VF-MCPC $-/ \mathrm{D}^{-}$ & $\begin{array}{l}\text { VF39SM, mcpC::SSp, mcpD:: } \Omega \mathrm{Nm} ; \mathrm{Sp}^{\mathrm{r}} \\
\mathrm{Nm}^{\mathrm{r}}\end{array}$ & This work \\
\hline \multicolumn{3}{|l|}{ Plasmids } \\
\hline pJQ200mp18 & Suicide vector with $s a c B$ system; $\mathrm{Gm}^{\mathrm{r}}$ & Quandt \& Hynes (1993) \\
\hline pJQ200SK & Suicide vector with $s a c B$ system; $\mathrm{Gm}^{r}$ & Quandt \& Hynes (1993) \\
\hline pRK7813 & Broad-host-range cloning vector $; \mathrm{Tc}^{\mathrm{r}}$ & Jones \& Gutterson (1987) \\
\hline pBSIISK $(+)$ & Cloning vector; $A p^{r}$ & Stratagene \\
\hline MCPB.B & $\begin{array}{l}8 \mathrm{~kb} \text { VF39SM BamHI fragment cloned in } \\
\text { pBSIISK }(+) \text {; contains a fragment of } m c p B\end{array}$ & This work \\
\hline VGL-747 & $\begin{array}{l}\text { VF39SM cosmid clone in pRK7813; cosmid } \\
\text { contains the entire } m c p B \text { gene }\end{array}$ & This work \\
\hline MCPB.E & $\begin{array}{l}1.8 \mathrm{~kb} \text { VF39SM EcoRI fragment cloned in } \\
\text { pBSIISK }(+)\end{array}$ & This work \\
\hline MCPC.B & $\begin{array}{l}6.7 \mathrm{~kb} \text { VF39SM BamHI fragment cloned in } \\
\text { pBSIISK(+) }\end{array}$ & This work \\
\hline MCPC.E & $\begin{array}{l}3 \mathrm{~kb} \text { VF39SM EcoRI fragment cloned in } \\
\text { pBSIISK }(+)\end{array}$ & This work \\
\hline MCPD.B & $\begin{array}{l}7 \text { kb VF39SM BamHI fragment cloned in } \\
\text { pBSIISK }(+)\end{array}$ & This work \\
\hline MCPD.P & $\begin{array}{l}2 \cdot 5 \text { kb VF39SM PstI fragment cloned in } \\
\text { pBSIISK }(+)\end{array}$ & This work \\
\hline MCPE.B & $\begin{array}{l}5 \text { kb VF39SM Bam HI fragment cloned in } \\
\text { pBSIISK }(+)\end{array}$ & This work \\
\hline MCPE.C & $\begin{array}{l}1.7 \mathrm{~kb} \text { VF39SM ClaI fragment cloned in } \\
\text { pBSIISK }(+)\end{array}$ & This work \\
\hline MCPF.B & $\begin{array}{l}6.7 \mathrm{~kb} \text { VF39SM Bam HI fragment cloned in } \\
\text { pBSIISK }(+)\end{array}$ & This work \\
\hline MCPF.PL & $\begin{array}{l}1.2 \mathrm{~kb} \text { VF39SM PstI fragment cloned in } \\
\text { pBSIISK }(+)\end{array}$ & This work \\
\hline $\mathrm{MCPB} \Omega \mathrm{TC}$ & $\begin{array}{l}\Omega T c \text { cassette cloned in internal Not } \mathrm{I} \text { site of } \\
\text { MCPB.E; contained in pJQ200mp18 }\end{array}$ & This work \\
\hline $\mathrm{MCPC} \Omega \mathrm{Sp}$ & $\begin{array}{l}\Omega \text { Sp cassette cloned in internal Xhol site of } \\
\text { MCPC.E; contained in pJQ200SK }\end{array}$ & This work \\
\hline $\mathrm{MCPD} \Omega \mathrm{Nm}$ & $\begin{array}{l}\Omega N m \text { cassette cloned in internal HindIII site of } \\
\text { MCPD.P; contained in pJQ200SK }\end{array}$ & This work \\
\hline MCPE $\Omega$ Sp & $\begin{array}{l}\Omega \text { Sp cassette cloned in internal Sma I site of } \\
\text { MCPE.C; contained in pJQ200SK }\end{array}$ & This work \\
\hline
\end{tabular}

*Antibiotics: Ap, ampicillin; Gm, gentamicin; Nm, neomycin; Sp, spectinomycin; St, streptomycin; Tc, tetracycline. 
PCR. The primer sequences used were $5^{\prime}$-CATGGTCTTCTCGGCAGCTTGCG-3' and 5'-GAATCGCCGACCAGACCAACC- $3^{\prime}$, and PCR cycling conditions were $1 \mathrm{~min}$ at $94^{\circ} \mathrm{C}$, $30 \mathrm{~s}$ at $60^{\circ} \mathrm{C}$ and $1 \mathrm{~min}$ at $72^{\circ} \mathrm{C}$ for 30 cycles. Using the protocol outlined by Boehringer Mannheim, the amplified product was PCR labelled with DIG. The DIG-labelled product was gel-purified using band interception as described by Sambrook et al. (1989) and was subsequently used as a probe to identify MCP-encoding genes from a size selected partial genomic library of VF39SM.

The partial genomic library was constructed by digesting VF39SM genomic DNA with BamHI to completion. The digest was electrophoresed in $0.8 \%$ agarose gel and the smear of fragments ranging in size from 5 to $12 \mathrm{~kb}$ was isolated using Prep-a-Gene (Bio-Rad). The fragments were ligated to BamHI-digested pBSIISK $(+)$. The ligation products were used to transform E. coli DH5 $\alpha$.

A putative MCP-encoding gene was isolated from this first round of screening, and named $m c p B$. Its identity was verified by subcloning and sequencing the region that hybridized to the PCR probe. The subcloned DNA was labelled by the random primer method (Boehringer Mannheim) and used to reprobe the partial genomic library. This second round of screening discovered four previously undetected putative MCPencoding genes, termed $m c p C$ through $m c p F$. Each fragment was subcloned and sequenced to identify regions of homology to MCP-encoding genes. New primers C1 ( $5^{\prime}$-AGGCGGACCGAGCAGCAGGC-3') and C2 (5'-CT'TGATTTCCTTTGCCGC-3') were designed from the DNA sequence of $m c p D$ and were used to create a new PCR-amplified probe from VF39SM genomic DNA. PCR cycling parameters were as described above. Subsequently, this probe was used to probe a complete genomic library of VF39SM.

Preparation of a VF39SM genomic library. Total genomic DNA from VF39SM was partially digested with Sau3AI to give a maximum number of fragments in the $30-40 \mathrm{~kb}$ size range. The fragments were ligated to the dephosphorylated cosmid pRK7813. The ligation mixture was packaged in vitro using the Boehringer Mannheim packaging kit according to the manufacturer's recommendation. Titration of the genomic library yielded approximately 2500 c.f.u. Cosmid DNA was isolated as alkaline lysis minipreps from 1000 independent tetracycline-resistant clones and verified on $0.8 \%$ agarose gels. Cosmid DNA from each individually purified clone was then dot-blotted on positively charged membranes. Two membranes contained 400 clones each and a third membrane contained the remaining 200 clones in the library. The membranes were dried for $30 \mathrm{~min}$ at $120^{\circ} \mathrm{C}$.

Insertional mutagenesis of VF39SM mcp genes. $m c p$ genes were mutated by inserting antibiotic-resistance cassettes into the ORFs of the cloned $m c p$ genes. The antibiotic-resistance cassettes used were those developed by Prentki \& Krisch (1984) and Fellay et al. (1987). The gene replacement in VF39SM was performed using a suicide vector and a positive selection strategy (Quandt \& Hynes, 1993) for double homologous recombinational events. Southern blotting (data not shown) was used to verify the replacement of the wild-type gene with the mutant gene.

Nodulation competition experiments. Peas (Pisum sativum cv. Trapper) were surface-sterilized by washing in $50 \%$ bleach for $5 \mathrm{~min}$, then with $70 \%$ ethanol, followed by three rinses in sterile distilled water. The seeds were germinated on water agar plates for $3 \mathrm{~d}$ and then transferred to modified magenta jars which were modelled to resemble Leonard jars (Vincent, 1970). The peas were grown in a vermiculite substrate.

After transfer to the magenta jars the germinating pea seeds were inoculated with the appropriate VF39SM strains. For competition experiments, the wild-type was co-inoculated with the $m c p$ mutant in a 1:1 ratio. The ratios were confirmed by performing viable plate counts on the inoculum. The inoculated peas were then grown for 5 weeks, after which the nodules were harvested, surface-sterilized and crushed. The macerate was plated on the appropriate selective media to determine whether the wild-type or the mcp mutant strain had formed the nodule. For each competition experiment 100 nodules were crushed and plated.

\section{RESULTS}

\section{Cloning of putative mcp genes}

PCR reactions using VF39SM genomic DNA and the dcrA primers (Dolla et al., 1992) amplified a single fragment approximately $350 \mathrm{bp}$ in size. This fragment was used to probe a genomic blot of VF39SM digested with a variety of restriction endonucleases. Digestion of VF39SM genomic DNA with BamHI gave at least seven hybridizing bands ranging in size from 5 to $12 \mathrm{~kb}$ (data not shown). Consequently, to enrich for fragments of this size a size-fractionated library of VF39SM was created. Four hundred colonies containing inserts, based on blue/white selection, were included in the library. Five putative $m c p$ clones were subsequently isolated from this library. Fig. 1 provides restriction maps of $m c p B$ through $m c p F$. Fifteen additional clones showing homology to an $m c p D$ probe (all unique based on the size of the hybridizing fragment) were identified from a cosmid library of VF39SM. No further characterization

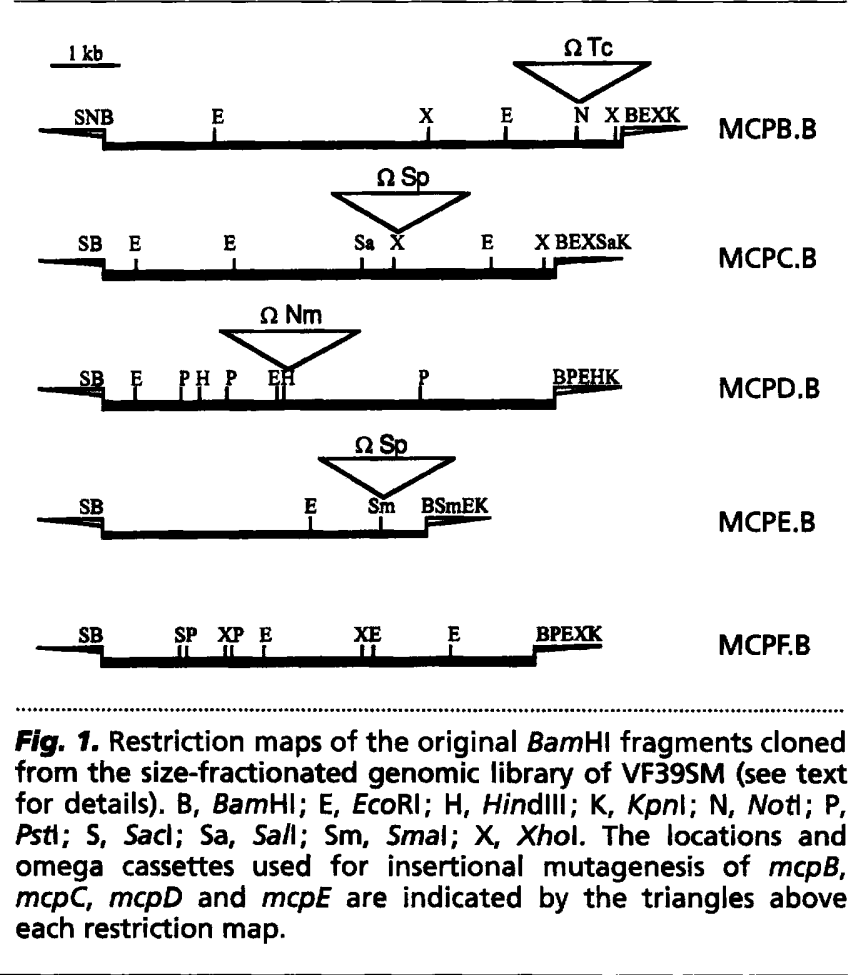




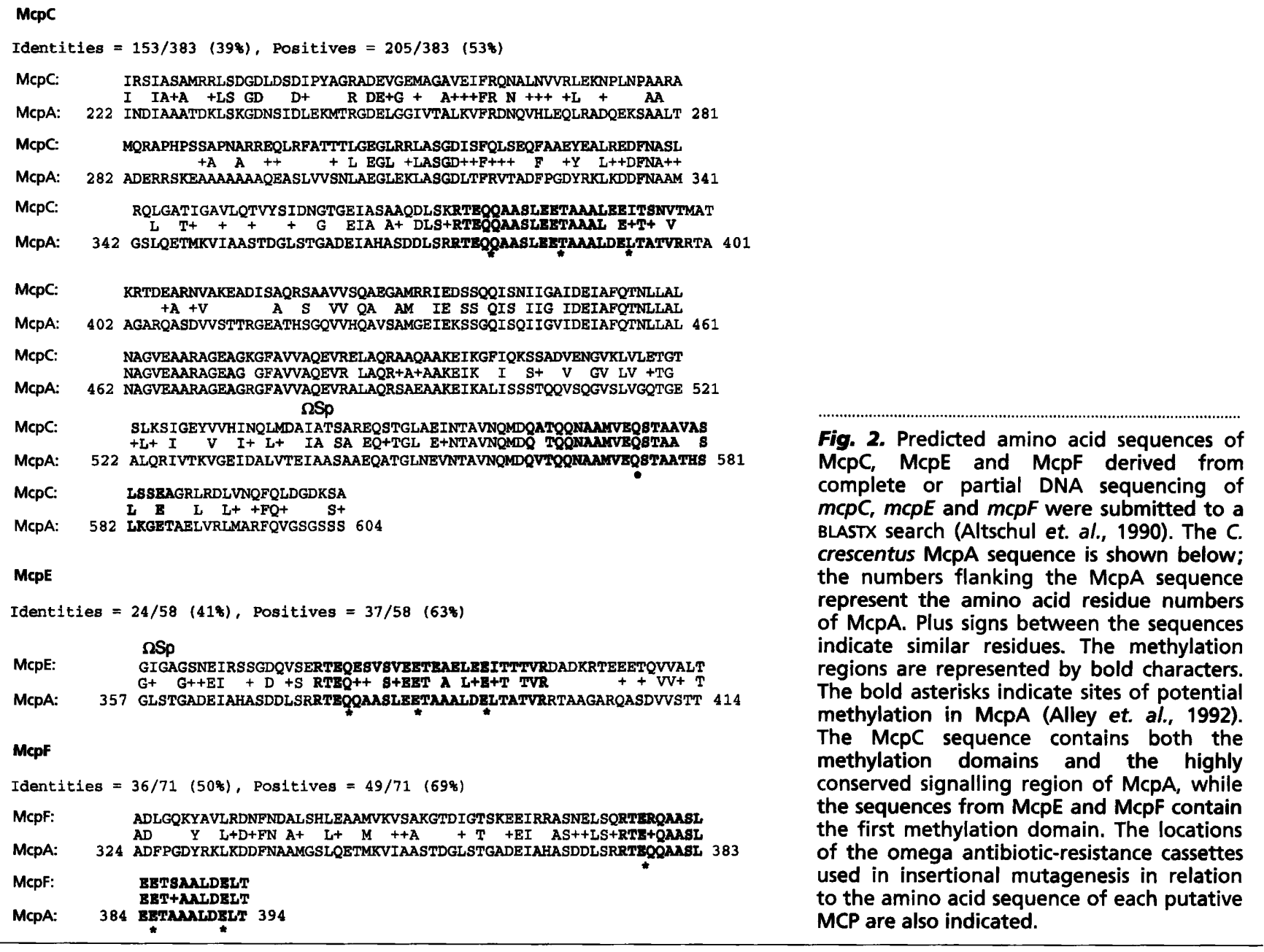

of any of these clones is available to verify that they code for MCPs.

\section{Sequencing of the mcp clones}

The BamHI fragments originally cloned from the VF39SM partial genomic library, labelled MCPB.B through MCPF.B, were subcloned to isolate smaller restriction fragments that hybridized to the $\operatorname{dcr} A$ primer derived PCR probe. The subclones were then sequenced from vector T7 or T3 primers, and deduced amino acid sequences were analysed by BLASTX for homology with protein databases. High similarities were reported to sequences of known MCPs. The highest alignment scores occurred with MCP sequences from $R$. leguminosarum (Brito et al., 1996), Rhodobacter capsulatus (Michotey et al., 1996) and Caulobacter crescentus (Alley et al., 1992). Sequence alignments of $\mathrm{McpC}, \mathrm{McpE}$ and McpF with McpA of C. crescentus are shown in Fig. 2. The nucleotide sequence of $m c p B$ has been deposited in GenBank (accession number AF022807). DNA sequence data were obtained using the clone MCPB.B and from a genomic cosmid clone carrying the entire $m c p B$ gene. The predicted $\mathrm{McpB}$ protein is 716 aa in length with a molecular mass of
$76.7 \mathrm{kDa}$. Based on a Kyte-Doolittle plot, two transmembrane domains are present. These encompass amino acid residues $18-37$ and 298-317. The area flanked by the transmembrane domains is, therefore, 261 aa in size and is presumably located in the periplasm. The complete DNA sequence of $m c p C$ (GenBank accession number AF036168) indicates that it encodes a protein containing two predicted transmembrane regions in the amino-terminal domain, and has all the characteristics common to known MCPs: a periplasmic amino-terminus, putative methylation domains, and a conserved signalling domain.

The $m c p D$ gene sequence has been deposited in GenBank (accession number U81828). Two potential translational start sites exist for the $m c p D$ ORF. The first is the ATG codon at nt 40 , while the second is an ATG start codon at nt 61 . Neither is preceded by a strong ribosome-binding site. The gene is, however, expressed in VF39SM as indicated by a promoterless lacZ fusion to $m c p D$ (data not shown). The predicted protein based on the first start codon has 624 amino acids and a molecular mass of $66 \cdot 3 \mathrm{kDa}$. A KyteDoolittle plot predicts two transmembrane regions, the first from residues 1 to 26 or 8 to 26 , depending on the transcriptional initiation site. The second trans- 
MсрB

McpD

R.I. McpA

C.c. MсpA

Tsr

MсpB

McpD

R.I. McpA

C.c. McpA

Tsr

McpB

McpD

R.I. McpA

C.c. McpA

Tsr

MсрB

McpD

R.I. McpA

C.c. McpA

Tsr

McpB

McpD

R.I. McpA

C.C. McpA

Tsr

MсpB

McpD

R.I. McpA

C.c. MсрA

Tsr

McpB

McpD

R.I. McpA

C.c. McpA

Tsr

MсpB

McpD

R.I. McpA

C.c. McpA

Tsr

MсpB

McpD

R.I. McpA

C.c. MсpA

Tsr

McpB

McpD

R.I. McpA

C.c. McpA

Tsr

McpB

McpD

C.C. MсpA 398

Tsr

317

McpB $\quad 550$

McpD $\quad 430$

R.I. MCPA 444

C.C. McpA 448

Tsr
M

MMI HFWNKFGIRAQITS GEVPLILIMSLLTVSAISGMNGLASIFSSYRAT

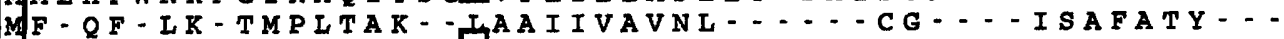
$M K$ - H I S IV - GKFFIIMAVFGVMAIGITF-.... YQSRQMLKVNDSY ..

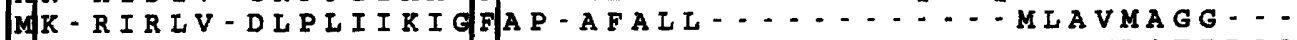
MIKRIKIVTSL - ILVIA VEGILQITSGGLFFNALKNDKENFTVIQTIRQQ

AGOSIAISDYSDORNEIOMSAEAFRSTPTOAVVDRFRAGVKAFDADDPRF

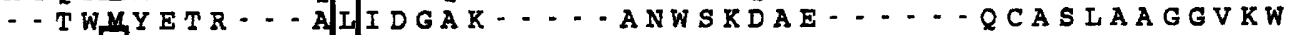

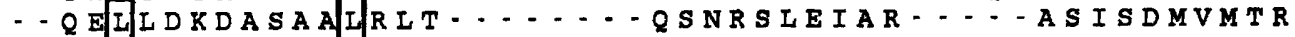
- A IIVOKSOSAALKOVVE-...R DMRONLEIORISKRISNINGEIFVV QST - IN S S W VALIQTRNTLNRAGIRYMMDQNNIGSGSTVAELMESASISL

AGNKDL $Q S V L A A I R Q D I T Y G K A F E E I V A L Q A R R D A L I S K V T E F G P W T S I$ GKANAAREAY SIYRDD|PSIDIVQFAAFNA ........ EPAXVDTWTRD

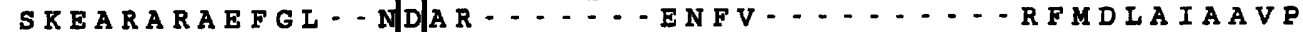
MTHKAGNIDVDK - NDARMAAVLVETDAV ......... KKDLLALKSKL

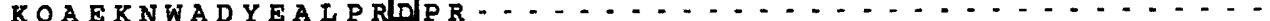

ALNDVVRSAWRONDVPLIOMTAATLEALNRSLYFSERFVHSDDFAAYDTA G I S GI PT ............................ X D IATR I SAK E Q S E I PK … . . . . . . . . . . . . . I K A D GF S V T D T C

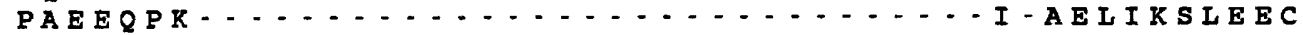
$\ldots \ldots \ldots$. $\ldots \ldots \ldots$ S A A A $\ldots \ldots$ I I R N I D I Y

QAALAEAVTLNEAAAKAAKNEIQKKRLMGAGQLMQNYTARLGDMKDVLQA P.-. - ERTTIDDSGISAGVVTIIAPLPIDKSG- - KAAGYIVTNWSV... G-. - AAIAVGRGATSEAELAMVQQIYLTLCQ- - PAFAAISPRFTSV-.R-... SAIDTVSGMIS - VDFNMAAG - FIAPEE- EQYVKMTGQIDQVVAA HNALAELIQLIGAGKINEFFDQP T QGYQD- G FEKQYV-..... AYMEQ SGNIROTOLSVLAPKISGGFKDLOATVTGAQKTLDGSVDATVASATSTTL $\ldots$ E........ I A A E VR $Q K$ K

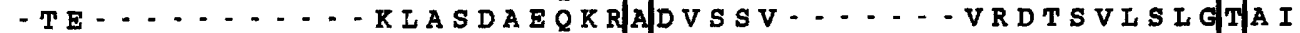

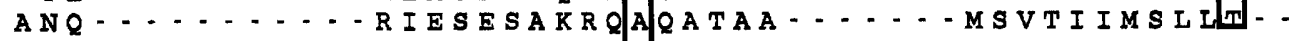

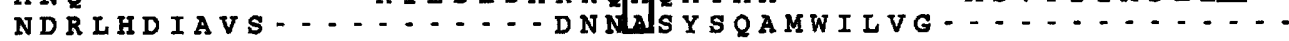

IISGLIIVIGIVISYFVGRLISSAVRNMAQSMEQLARGEERIVITGVEHR SVITAIAVIAFLIA- - MRSIVGRPIRVISERISALOKGDIAS PVTYKENG AALFAVSCFGFI-A - IRAWLVKPIKQMVTTMKVIADGDLTSTVEGTIRR - I GAVGA LAFL-T- - VMT-TRKSINDIAAATDKLSKGDNSIDLEKMTRG - VMIVVIAVIGA VWFGIKASIVAPMNRLIDSIRHIAGRDIVKPIE - VDGS

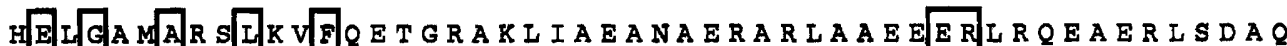
$D E I G F$ A R I I V F R EAIAKVEREQAAAEQSASLDAERARNALFTEEASN

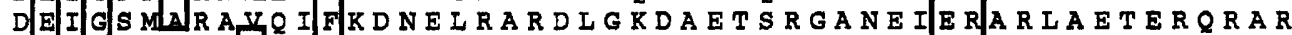
DEI $G G$ IVT A I K VIR D NQVHLEQLRADQEKSAALTADLBR S K EAAAAAAAO

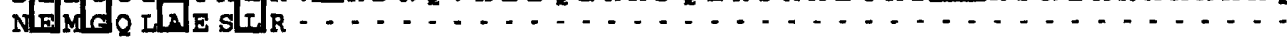

VMEHAFRQISVGIDAIS KADITVRVGE - VDHRYVRIRDFFANSVA S⿴囗十⺝EA TORLVMTALANSIEKIAACDFSIKIAD - LGPEFDKLRODFNNMVEAKAAA DMAEATSGIAEGLR HIADGNLVFSLDDKFAEDFEPLRANFNAAVAQLAES

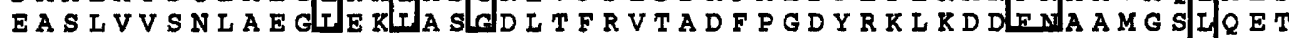

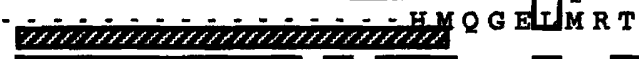
VDAVIRAVGTIRSGLAEISTAS NDIARTEQQAASLEETVAAGEVTRGV

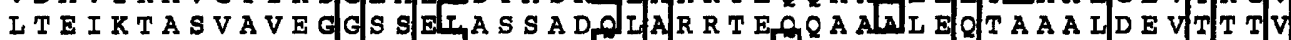

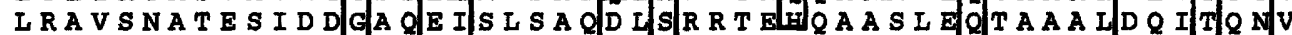
MKVIAASTDGLSTGA DEIAHAS D DSLRTEQQAASLEETAAAIDE T A TV

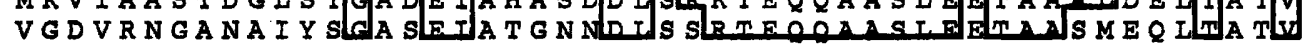

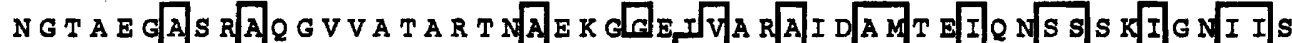

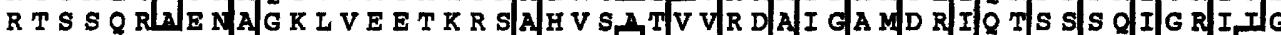

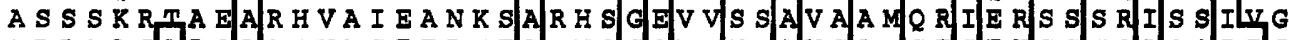

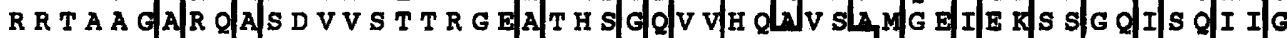

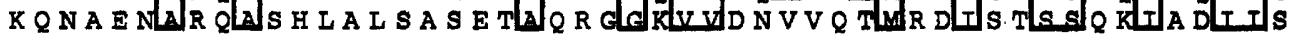

VIDEIAFQTNLLALNAGVEAARAGEAGKGFAVVAQEVRELAQRSANAARE

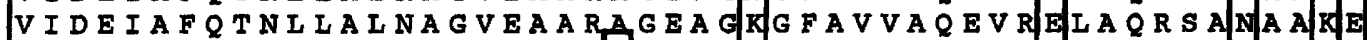

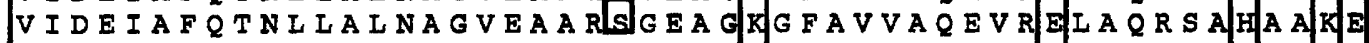

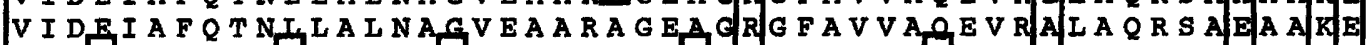
VI

Fig. 3. Continued on facing page. 
membrane domain extends from residue 179 to 201 . Based on these observations, McpD should contain a periplasmic domain of approximately 147 aa.

The sequence alignment in Fig. 3 shows the strong similarity of the McpB and McpD protein sequences to the C. crescentus McpA sequence (Alley et al., 1992), the $R$. leguminosarum McpA (Brito et al., 1996), and the $E$. coli Tsr sequence (Boyd et al., 1983). The strongest similarities occur within the methylation and signalling domains of the MCPs.

\section{Mutagenesis of the mcp genes}

$m c p B, m c p C, m c p D$ and $m c p E$ were mutated via insertional mutagenesis, using antibiotic-resistance cassettes as the selectable markers (Prentki \& Krisch, 1984). Restriction endonuclease sites used for insertions of antibiotic resistance cassettes were ascertained from the sequence data generated in this study. Figs 1 and 2 indicate the location of gene disruption sites in each $m c p$ clone. Insertion of the $\Omega T c$ fragment into the Not I site of $m c p B$ disrupted the gene within the putative second methylation site. The $\Omega S p$ fragment was inserted just downstream of the highly conserved domain of $\operatorname{mcp} C$ using a XhoI site. In $m c p D$ the $\Omega \mathrm{Km}$ cassette inserted at the HindIII site ahead of the first methylation region. With $m c p E$, insertional mutagenesis also occurred using a Smal site located slightly upstream of the first methylation region. In addition to the single gene knockouts created, an $m c p C, m c p D$ double mutant was obtained. The mutant was created by mating
$\mathrm{MCPD} \Omega \mathrm{Nm}$ into VF-MCPC ${ }^{-}$, and then selecting for double recombinants.

Phenotypic analysis of the mutants was performed using VMM swarm plates to assess chemotactic behaviour towards various carbon sources (adonitol, arabinose, arginine, aspartate, erythritol, galactose, glutamate, glycerol, histidine, maltose, manitol, melibiose, ornithine, raffinose, ribose, rhamnose, serine, sorbitol and trigonelline). To date, phenotypes for mutations in $m c p C, m c p D$ and $m c p E$ have not been identified. However, a mutation in $m c p B$ inhibited chemotaxis to all carbon sources tested. This phenotype does not conform to the $E$. coli model whereby a MCP is responsive to a specific set of ligands. Fig. 4 provides examples of the swarming patterns of the mutants. VF$\mathrm{MCPB}^{-}$is impaired in its ability to swarm away from the inoculation point. Cells accumulate in a localized area, resulting in a denser circle of growth relative to the wild-type and the other mutant strains. This is particularly evident in plate (a). In addition, the swarm diameter of VF-MCPB- is smaller relative to the other strains. This behaviour is most pronounced in the raffinose swarm plate.

Possible effects on the ability of the mcp mutants to interact with legume host plants were assayed by nodulation competition tests. The principle of this type of study is that if a plant is co-inoculated with two strains of rhizobia, formation of more nodules by one strain indicates greater 'competitiveness'; this may be due to a variety of factors, including faster growth in the

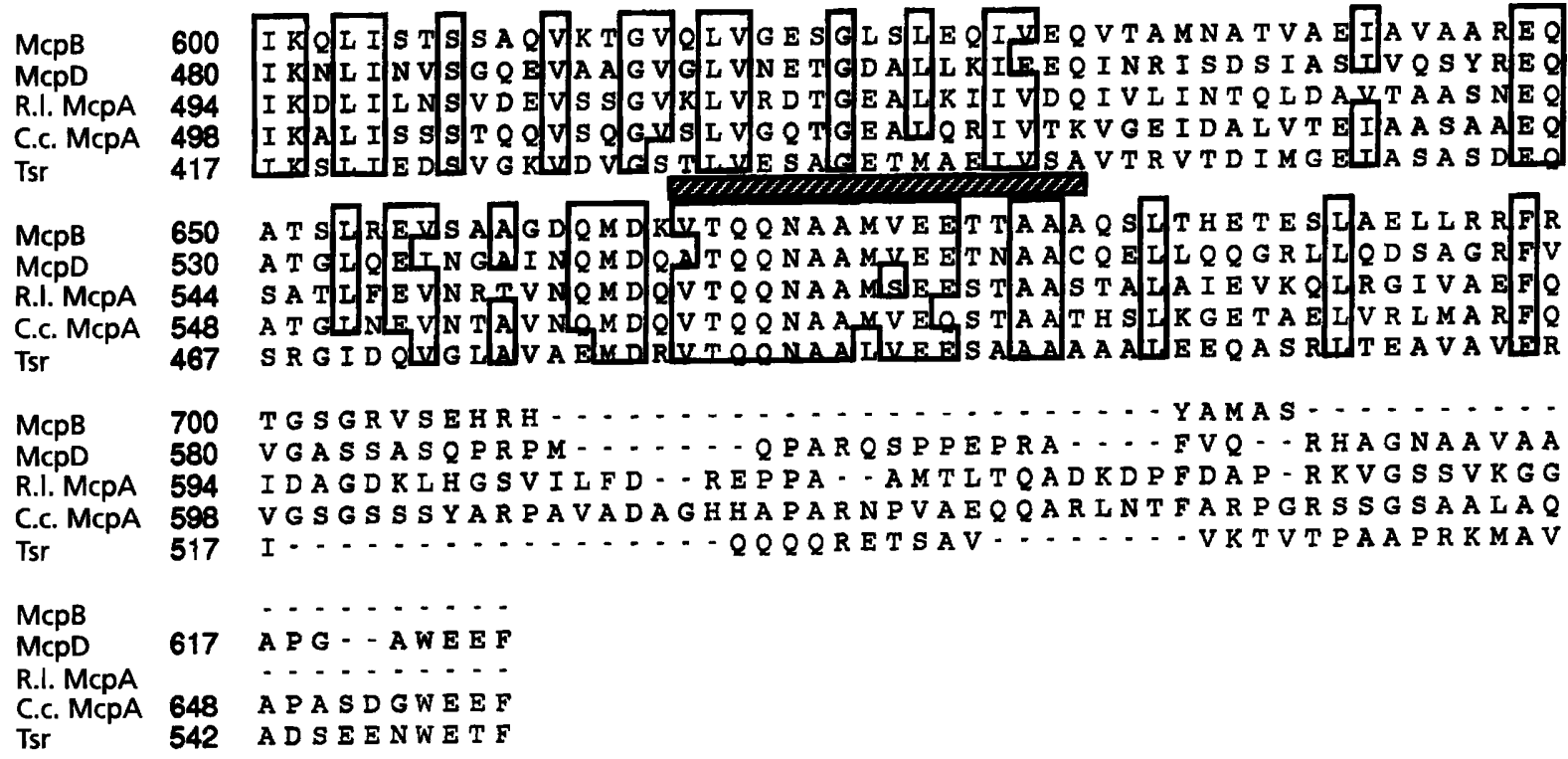

Fig. 3. Amino acid sequence alignment of McpB and McpD with $R$. leguminosarum McpA, $C$. crescentus McpA, and $E$. coli Tsr. The shaded rectangular boxes denote the approximate location of the transmembrane domains for each MCP. The hatched rectangular boxes indicate the methylation regions of each MCP. The boxed residues indicate identical amino acids among the five chemotaxis proteins. McpB and McpD have high homology to the methylation domains and signalling domain of both of the McpA proteins and of Tsr. The sequence alignment was performed using the CLUSTAL $V$ program, and displayed using the SeqVu program (Garvan Institute). 

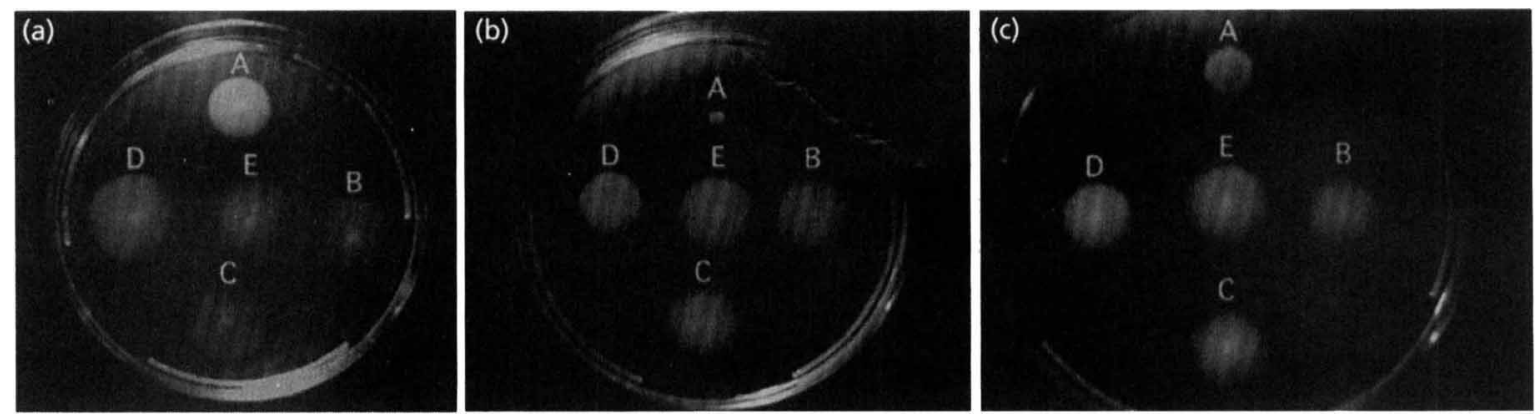

Fig. 4. Swarm plates showing the chemotactic behaviour of the various VF39SM MCP mutants. Strains are labelled as follows: A, VF-MCPB ${ }^{-}$; B, VF-MCPC ; C, VF-MCPD $;$D, VF-MCPE ${ }^{-}$; E, VF39SM. (a) Yeast extract swarm plate. (b) VMM raffinose swarm plate. (c) VMM adonitol swarm plate. The swarm plates were prepared as described in Methods.

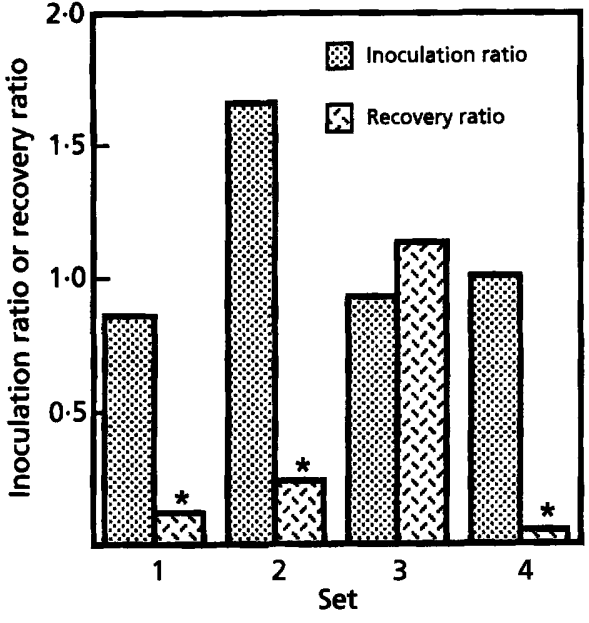

Fig. 5. Nodulation competition experiments: inoculation and recovery ratios of mcp mutants versus the wild-type VF39SM. Trapper peas were co-inoculated with VF39SM and an individual mcp mutant strain as described in Methods. The mcp mutants co-inoculated were as follows: set 1, VF-MCPB-; set 2, VF-MCPC $^{-}$; set 3, VF-MCPD ${ }^{-}$; set 4, VF-MCPC-/D ${ }^{-}$. After 5 weeks incubation, 100 nodules were crushed to determine which strain formed each nodule. Since bacteria in each nodule are usually of clonal origin a selectable marker can be used to determine the number of nodules formed by a strain. Ratios are expressed as the mcp mutantNF39SM. An asterisk indicates that the recovery ratio differed significantly from the initial inoculation ratio. Statistical significance was confirmed using the chi-squared test.

root environment, faster infection rates, or superior ability to migrate towards suitable infection sites (Ames \& Bergman, 1981; Gulash et al., 1984; Dharmatilake \& Bauer, 1992). The results of the nodule competition experiments (Fig. 5) indicate that VF-MCPB ${ }^{-}$and VF$\mathrm{MCPC}^{-}$were unable to compete with VF39SM in nodulation frequency. On control plants where VF$\mathrm{MCPB}^{-}$and VF-MCPC ${ }^{-}$were inoculated alone, the number and appearance of nodules were the same as for wild-type VF39SM, and they appeared just as rapidly. Therefore, the mutants were not impaired in nodulation or nitrogen fixation capacity per se. The recovery ratio of VF-MCPD ${ }^{-}$indicated that it was able to compete successfully with VF39SM for nodule occupancy. The inability of the $m c p C, m c p D$ double mutant to compete with VF39SM for nodule occupancy is consistent with the result of the $m c p C$ mutant competition experiment. $m c p E$ mutants were unaltered in competitive ability (data not shown).

\section{Localization of mcp genes to VF39SM plasmids}

Rhizobia characteristically contain large plasmids (Hynes et al., 1989; reviewed by Mercado-Blanco \& Toro, 1996). Some are involved in symbiosis, while the function of other plasmids has been less well studied. VF39SM contains six plasmids, ranging in size from $150 \mathrm{~kb}$ to over $600 \mathrm{~kb}$ (Hynes et al., 1988). To investigate whether any putative $m c p$ genes reside on VF39SM plasmids, a mixture of probes derived from the six indigenous plasmids of VF39SM was used to probe a blot containing the putative $m c p$ genes (data not shown). The results of this experiment indicated that $m c p C$ is plasmid localized. When a typical Eckhardt gel of VF39SM and the plasmid-cured derivative strains developed by Hynes \& McGregor (1990) was probed with a fragment from MCPC.B, $m c p C$ was found to reside on pRleVF39f (Fig. 6). Additionally, three of the 15 cosmid clones which hybridized to the $m c p D$ probe were of plasmid origin (data not shown).

\section{DISCUSSION}

Our results provide evidence for the existence of a family of $m c p$-like genes in R. leguminosarum VF39SM. Positive hybridization to a probe containing DNA corresponding to the conserved signalling domain of MCPs, and sequence similarities between MCPs and the deduced amino acid sequences for $\mathrm{McpB}$ through $\mathrm{McpF}$, suggest that these genes do code for MCP-like proteins. 


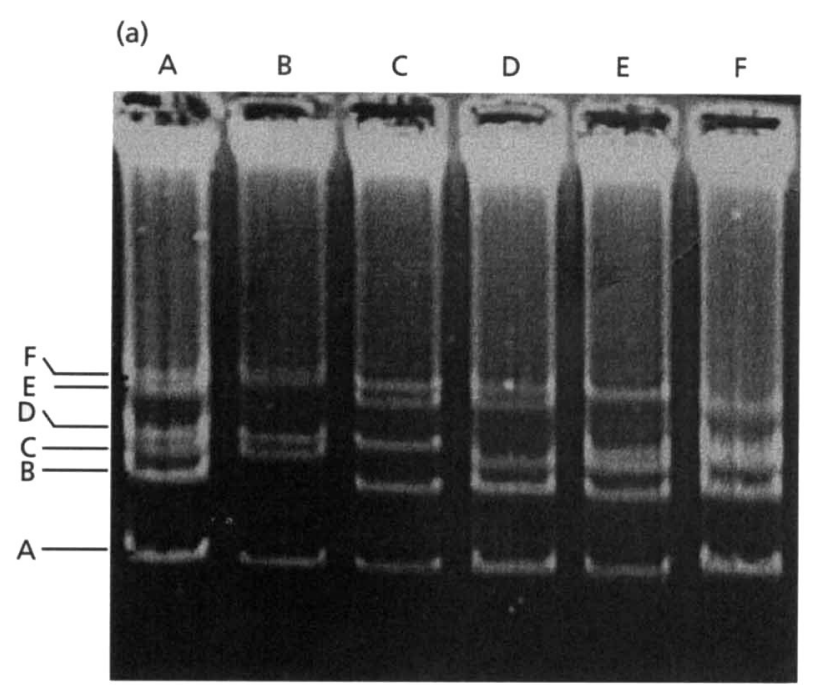

(b)

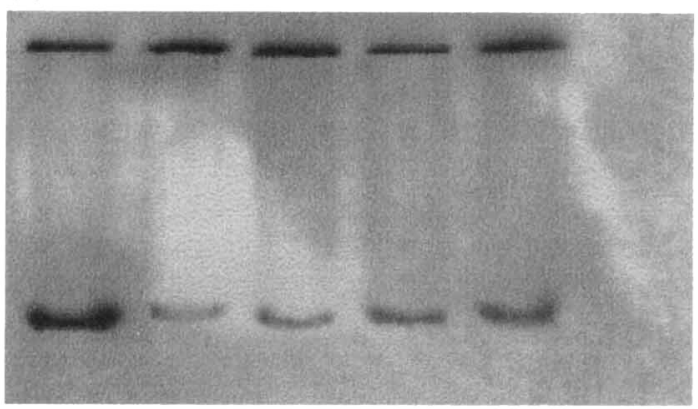

Fig. 6. (a) Typical Eckhardt gel showing VF39SM and the plasmid-cured derivative strains prepared by Hynes \& McGregor (1990). The strain in each lane is as follows: A, VF39SM; B, LRS39201 (cured of pRleVF39b); C, LRS39301 (cured of pRleVF39c); D, LRS39401 (cured of pRleVF39d); E, LRS39501 (cured of pRleVF39e); F, LRS39601 (cured of pRleVF39f). (b) Southern blot of an Eckhardt gel with the same strain order as that in (a) probed with the $1.5 \mathrm{~kb}$ ECORI fragment of MCPC.B. A band is present in all lanes except that (F) containing LRS39601. The letters A-F indicate the positions of the six plasmids of strain VF39 (pRleVF39a, pRleVF39b, etc.) as described by Hynes et al. (1988).

In addition, the identification of 15 further clones showing homology to the highly conserved domain of $m c p$ genes strongly suggests that, as in Desulfovibrio (Deckers \& Voordouw, 1994) and Halobacterium (Zhang et al., 1996), Rhizobium spp. may contain numerous genes encoding proteins showing similarity to MCPs. Further evidence for this comes from recent publications showing that genes homologous to the $m c p$ genes we have identified are present on the nodulation plasmids of another strain of $R$. leguminosarum (Brito et al., 1996) and of Rhizobium sp. NGR234 (Freiberg et al., 1997); also, genes encoding proteins with amino acid sequence similarity to the signalling domain of MCPs in S. meliloti have been described (Greck et al., 1995). None of these genes appears to be closely related to any of the genes from strain VF39SM for which we have complete or partial sequence data. Further investigation will be required before a role (if any) for these genes in chemotaxis can be defined. We do believe that the majority of the clones we have identified from VF39SM code for proteins with homology to MCPs for two reasons: (1) Western blots using antibodies against the MCP highly conserved domain reveal the presence of at least 10 proteins that react with the antibody (data not shown); and (2) most clones hybridized at least as strongly to several $m c p$-derived probes as did the five genes for which we have DNA sequence data. Since five clones chosen more or less at random from those hybridizing with $m c p$ probes code for MCP-like proteins, it is highly probable that some of the other clones do so as well. However, it is also possible that some of the clones carrying DNA homologous to $m c p$ genes are pseudogenes, or code for proteins like the $t c p 1$ and $a c f B$ gene products in Vibrio cholerae (Harkey et al., 1994; Everiss et al., 1994), which show similarity to the MCP signalling domain, but apparently do not function as chemoreceptors, although they have important roles in other facets of signal transduction.

All the putative $m c p$ genes for which DNA sequencing (complete or partial) was carried out had high homology to the methylation domains characteristic of MCPs. The amino acid sequences deduced from the DNA sequences of $m c p B, m c p C$ and $m c p D$ show all the characteristic features of MCPs, such as transmembrane domains, methylation sites, and the signalling domain. The genes also code for proteins of a size typical for MCPs. Of the other putative MCP-encoding genes so far identified in the rhizobia, those from $S$. meliloti (Greck et al., 1995) appear unusual in that the methylation sites and transmembrane regions are missing, whereas those from NGR234 (Freiberg et al., 1997) and R. leguminosarum bv. viciae UPM791 (Brito et al., 1996) appear to code for fairly typical MCPs.

Our results suggest that some of the mcp genes we have identified play a role in chemotaxis. While mutations in $m c p C, m c p D$ and $m c p E$ conferred no alteration in chemotactic properties towards a variety of sugars, amino acids and other carbon sources, mutations in $m c p B$ appeared to create a general chemotactic block. The reason for this remains unclear, but $m c p B$ mutations resemble $m c p A$ mutants in Rhodobacter sphaeroides (Ward et al., 1995), which lost chemotaxis to a wide range of carbon sources, rather than a discrete set. In addition, this phenotype was apparent only under aerobic conditions. This suggests that the role of certain MCPs in chemotaxis of members of the alpha sub-group of the proteobacteria may deviate significantly from the E. coli paradigm.

Further evidence that several of the $m c p$ genes we have identified have a biological function comes from our nodulation competition experiments. It has long been speculated that chemotaxis may play a role in competition between Rhizobium strains in the legume rhizosphere, and indeed some studies (Ames \& Bergman, 1981; Caetano-Anollés et al., 1988; Bauer \& Caetano-Anollés, 1990) have shown that non-motile and some non-chemotactic strains cannot compete success- 
fully with their wild-type counterparts. Our results establish not only that chemotaxis per se is important in competition for nodulation, but that subtle, and as yet uncharacterized, effects on chemotactic behaviour may also affect competitiveness. Not only was the $m c p B$ (chemotaxis minus) mutant greatly reduced in its ability to compete, but the mutations in $m c p C$, which caused no apparent chemotactic phenotype in laboratory assays, also had drastic effects on competition for nodule occupancy. This suggests that these genes may code for proteins that sense highly specific compounds in the plant environment, and that chemotaxis towards these compounds may be an important aspect of signal exchange between plant and bacterial partners in the symbiosis.

Identifying ligands for a large family of putative chemoreceptors could prove to be a daunting task, given the great metabolic diversity of Rhizobium species (Stowers, 1985; Parke \& Ornston, 1984), and the wide diversity of compounds that can serve as chemoattractants for rhizobia (Parke et al., 1985). Adding to the difficulty, some of the potential chemoattractants may be compounds from root exudates that have not yet been identified. The finding that certain putative $m c p$ genes are located on plasmids, both in strain VF39SM, as is the case for $m c p C$ and at least three other cosmid clones, and in other rhizobia (Brito et al., 1996; Freiberg et al., 1997) may be of some use in determining functions. It is not unlikely that $m c p$ genes located on plasmids code for proteins that sense attractants catabolized by enzymes encoded by those plasmids. Many catabolic genes have been mapped to plasmids in rhizobia (Murphy et al., 1987; Tepfer et al., 1988; Boivin et al., 1991; Charles \& Finan, 1991; Baldani et al., 1992), and the complete sequence of the nodulation plasmid from NGR234 suggests the presence of a large number of transport and catabolic genes (Freiberg et al., 1997). Strains cured of particular plasmids (e.g. Hynes \& McGregor 1990; Baldani et al., 1992) could be used to aid in identification of specific compounds in root exudates catabolized by plasmid-encoded genes, and these compounds could then be tested as chemoattractants.

This study has demonstrated that cloning genes based on their homology to DNA sequences encoding highly conserved regions in MCPs, and then analysing them by mutation and sequencing, provides a valid approach for detecting previously unidentified $m c p$-like genes in bacteria. Further work on each of the clones we have obtained will determine the precise role the putative $m c p$ genes play in chemotaxis and other cellular functions, and should establish conclusively whether a large family of such genes exists in rhizobia.

\section{ACKNOWLEDGEMENTS}

We thank Melanie Berndt and Christa Martindale for technical assistance, and Alberto Mendoza for many useful discussions. The financial support of a Natural Sciences and Engineering Council research grant to M.F.H. is gratefully acknowledged.

\section{REFERENCES}

Alam, M., Lebert, M., Oesterhelt, D. \& Hazelbauer, G. L. (1989). Methyl-accepting taxis proteins in Halobacterium balobium. EMBO J 8, 631-639.

Alley, M. R. K., Maddock, J. R. \& Shapiro, L. (1992). Polar localization of a bacterial chemoreceptor. Genes Dev 6, 825-836.

Altschul, S. F., Gish, W., Miller, W., Myers, E. W. \& Lipman, D. J. (1990). Basic local alignment search tool. J Mol Biol 215, 403-410.

Ames, P. \& Bergman, K. (1981). Competitive advantage provided by bacterial motility in the formation of nodules by Rizobium meliloti. J Bacteriol 148, 728-729.

Armitage, J. P., Gallager, A. \& Johnston, A. W. B. (1988). Comparison of the chemotactic behaviour of Rhizobium leguminosarum with and without the nodulation plasmid. Mol Microbiol 2, 743-748.

Baldani, J. I., Weaver, R. W., Hynes, M. F. \& Eardly, B. D. (1992). Utilization of carbon substrates, electrophoretic enzyme patterns, and symbiotic performance of plasmid cured clover R bizobium. Appl Environ Microbiol 58, 2308-2314.

Bauer, W. D. (1991). Motility and chemotaxis in the life of rhizobia. In Plant Biotechnology and Development, pp. 17-24. Edited by P. M. Gresshoff. Ann Arbor: CRC Press.

Bauer, W. D. \& Caetano-Anollés, G. (1990). Chemotaxis, induced gene expression and competitiveness in the rhizosphere. Plant Soil $129,45-52$.

Beringer, J. E. (1974). $\mathrm{R}$ factor transfer in Rhizobium leguminosarum. J Gen Microbiol 84, 188-198.

Boivin, C., Barran, L. R., Malpica, C. A. \& Rosenberg, C. (1991). Genetic analysis of a region of the Rhizobium meliloti pSym plasmid specifying catabolism of trigonelline, a secondary metabolite present in legumes. J Bacteriol 173, 2809-2817.

Boyd, A., Kendall, K. \& Simon, M. I. (1983). Structure of the serine chemoreceptor in Escherichia coli. Nature 301, 623-626.

Brito, B., Palacios, J.-M., Ruiz-Argueso, T. \& Imperial, J. (1996). Identification of a gene for a chemoreceptor of the methylaccepting type in the symbiotic plasmid of Rhizobium leguminosarum bv. viciae UPM791. Biochim Biophys Acta 1308, 7-11.

Caetano-Anollés, G., Wall, L. G., Micheli, A. T. D., Macchi, E. M., Bauer, W. D. \& Favelukes, G. (1988). Role of motility and chemotaxis in efficiency of nodulation by Rizobium meliloti. Plant Physiol 86, 1228-1235.

Caetano-Anollés, G., Wrobel-Boerner, E. \& Bauer, W. D. (1992). Growth and movement of spot inoculated Rhizobium meliloti on the root surface of alfalfa. Plant Physiol 98, 1181-1189.

Charles, T. C. \& Finan, T. (1991). Analysis of a 1600-kilobase Rhizobium meliloti megaplasmid using defined deletions generated in vivo. Genetics 127, 5-20.

Currier, W. W. \& Strobel, G. A. (1977). Chemotaxis of Rhizobium spp. to a glycoprotein produced by birdsfoot trefoil roots. Science 196, $434-435$.

Deckers, H. M. \& Voordouw, G. (1994). Identification of a large family of genes for putative chemoreceptor proteins in an ordered library of the Desulfovibrio vulgaris Hildenborough genome. $J$ Bacteriol 176, 351-358.

Dharmatilake, A. J. \& Bauer, W. D. (1992). Chemotaxis of Rhizobium meliloti towards nodulation gene-inducing compounds from alfalfa roots. Appl Environ Microbiol 58, 1153-1158. 
Dolla, A., Fu, R., Brumlik, M. J. \& Voordouw, G. (1992). Nucleotide sequence of $\operatorname{dcr} A$, a Desulfovibrio vulgaris Hildenborough chemoreceptor gene, and its expression in Escherichia coli. $J$ Bacteriol 174, 1726-1733.

Eckhardt, T. (1978). A rapid method for the identification of plasmid deoxyribonucleic acid in bacteria. Plasmid 1, 584-588.

Everiss, K. D., Hughes, K. J., Kovach, M. E. \& Peterson, K. M. (1994). The Vibrio cholerae acfB colonization determinant encodes an inner membrane protein that is related to a family of signal-transducing proteins. Infect Immun 62, 3289-3298.

Fellay, R., Frey, J. \& Krisch, H. (1987). Interposon mutagenesis of soil and water bacteria: a family of DNA fragments designed for in vitro insertional mutagenesis of gram-negative bacteria. Gene 52, 147-154.

Freiberg, C., Fellay, R., Bairoch, A., Broughton, W. J., Rosenthal, A. \& Perret, X. (1997). Molecular basis of symbiosis between Rhizobium and legumes. Nature 387, 394-401.

Greck, M., Platzer, J., Sourjik, V. \& Schmitt, R. (1995). Analysis of a chemotaxis operon in Rhizobium meliloti. Mol Microbiol 15, 989-1000.

Gulash, M., Ames, P., Larosiliere, R. C. \& Bergman, K. (1984). Rhizobia are attracted to localized sites on legume roots. $A p p l$ Environ Microbiol 48, 149-152.

Hanlon, D. W. \& Ordal, G. W. (1994). Cloning and characterization of genes encoding methyl-accepting chemotaxis proteins in Bacillus subtilis. J Biol Chem 269, 14038-14046.

Harkey, C. W., Everiss, K. D. \& Peterson, K. M. (1994). The Vibrio cholerae toxin-coregulated-pilus gene $t c p I$ encodes a homolog of methyl-accepting chemotaxis proteins. Infect Immun 62, 2669-2678.

Hazelbauer, G. L. (1988). The bacterial chemosensory system. Can J Microbiol 34, 466-474.

Hazelbauer, G. L., Yaghmai, R., Burrows, G. G., Baumgartner, J. W., Dutton, D. P. \& Morgan, D. G. (1990). Transducers: transmembrane receptor proteins involved in bacterial chemotaxis. In The Biology of the Chemotactic Response, pp. 107-134. Edited by J. P. Armitage \& J. M. Lackie. Cambridge: Cambridge University Press.

Hynes, M. F. \& McGregor, N. F. (1990). Two plasmids other than the nodulation plasmid are necessary for formation of nitrogenfixing nodules by Rhizobium leguminosarum. Mol Microbiol 4, 567-574.

Hynes, M. F., Simon, R. \& Pühler, A. (1985). The development of plasmid-free strains of Agrobacterium tumefaciens by using incompatibility with a Rhizobium meliloti plasmid to eliminate pAEC58. Plasmid 13, 99-105.

Hynes, M. F., Brucksch, K. \& Priefer, U. (1988). Melanin production encoded by a cryptic plasmid in a Rhizobium leguminosarum strain. Arch Microbiol 150, 326-332.

Hynes, M. F., Quandt, J., O'Connell, M. P. \& Puhler, A. (1989). Direct selection for curing and deletion of Rhizobium plasmids using transposons carrying the Bacillus subtilis sacB gene. Gene 78, 111-120.

Jones, J. D. \& Gutterson, N. (1987). An efficient mobilizable cosmid vector, $p R K 7813$, and its use in a rapid method for marker exchange in Pseudomonas fluorescens strain HV37a. Gene 61, 299-306.

Manson, M. D. (1992). Bacterial motility and chemotaxis. Adv Microb Physiol 33, 277-346.

Matsumura, P., Roman, S., Volz, K. \& McNally, D. (1990). Signaling complexes in bacterial chemotaxis. In The Biology of the
Chemotactic Response, pp. 135-154. Edited by J. P. Armitage \& J. M. Lackie. Cambridge: Cambridge University Press.

McCleary, W. R. \& Zusman, D. R. (1990). FrzE of Myxococcus xanthus is homologous to both CheA and CheY of Salmonella typhimurium. Proc Natl Acad Sci USA 87, 5898-5902.

McCleary, W. R., McBride, M. J. \& Zusman, D. R. (1990). Developmental sensory transduction in Myxococcus xanthus involves methylation and demethylation of FrzCD. J Bacteriol 172, 4877-4887.

Mercado-Blanco, J. \& Toro, N. (1996). Plasmids in Rhizobia: the role of nonsymbiotic plasmids. Mol Plant-Microbe Interact $\mathbf{9}$, $535-545$.

Michotey, V., Toussaint, B., Richaud, P. \& Vignais, P. M. (1996). Characterisation of the $m c p A$ and $m c p B$ genes capable of encoding methyl-accepting type chemoreceptors in $R$ bodobacter capsulatus. Gene 170, 73-76.

Morgan, D. G., Baumgartner, J. W. \& Hazelbauer, G. L. (1993). Proteins antigenically related to methyl-accepting chemotaxis proteins of $E$. coli detected in a wide range of bacterial species. J Bacteriol 175, 133-140.

Munoz Aguilar, J. M., Ashby, A. M., Richards, A. J. M., Loake, G. J., Watson, M. D. \& Shaw, C. H. (1988). Chemotaxis of Rhizobium leguminosarum biovar phaseoli towards flavonoid inducers of symbiotic nodulation genes. J Gen Microbiol 134, 2741-2746.

Murphy, P. J., Heycke, N., Banflavi, Z., Tate, M. E., de Bruijn, F., Kondorosi, A., Tempe, J. \& Schell, J. (1987). Genes for the catabolism and synthesis of opine-like compounds in Rhizobium meliloti are closely linked and on the sym plasmid. Proc Natl Acad Sci USA 84, 493-497.

Parke, D. \& Ornston, L. N. (1984). Nutritional diversity of Rhizobiaceae revealed by auxanography. J Gen Microbiol 130 , 1743-1750.

Parke, D., Rivelli, M. \& Ornston, L. N. (1985). Chemotaxis to aromatic and hydroaromatic acids: comparisons of Bradyrhizobium japonicum and Rhizobium trifolii. J Bacteriol $163,417-422$.

Parkinson, J. S. (1993). Signal transduction schemes of bacteria. Cell 73, 857-871.

Prentki, P. \& Krisch, H. M. (1984). In vitro insertional mutagenesis with a selectable DNA fragment. Gene 29, 303-313.

Priefer, U. B. (1989). Genes involved in lipopolysaccharide production and symbiosis are clustered on the chromosome of Rhizobium leguminosarum biovar viciae VF39. J Bacteriol 171, 6161-6168.

Quandt, J. \& Hynes, M. F. (1993). Versatile suicide vectors which allow direct selection for gene replacement in gram negative bacteria. Gene 127, 15-21.

Robinson, J. B. \& Bauer, W. D. (1993). Relationships between C4 dicarboxylic acid transport and chemotaxis in Rhizobium meliloti. J Bacteriol 175, 2284-2291.

Sambrook, J., Fritsch, E. F. \& Maniatis, T. (1989). Molecular Cloning: a Laboratory Manual, 2nd edn. Cold Spring Harbor, NY: Cold Spring Harbor Laboratory.

Simon, R., Priefer, U. \& Puhler, A. (1983). A broad host range mobilization system for in vivo genetic engineering: transposon mutagenesis in Gram negative bacteria. Bio/Technology 1, 784-791.

Stock, J. B., Lukat, G. S. \& Stock, A. M. (1991). Bacterial chemotaxis and the molecular logic of intracellular signal transduction networks. Annu Rev Biophys Biophys Chem 20, 109-136. 
Stowers, M. D. (1985). Carbon metabolism in Rhizobium species. Annu Rev Microbiol 39, 89-108.

Tepfer, D., Goldman, A., Pamboukdjian, N., Maille, M., Lepingle, A., Chevalier, D., Dénarié, J. \& Rosenberg, C. (1988). A plasmid of Rhizobium meliloti 41 encodes catabolism of two compounds from root exudate of Calystegium sepium. J Bacteriol 170, 1153-1161.

Vande Broek, A. \& Vanderleyden, J. (1995). The role of bacterial motility, chemotaxis, and attachment in bacteria-plant interactions. Mol Plant-Microbe Interact 8, 800-810.

Vincent, J. M. (1970). A Manual for the Practical Study of Rootnodule Bacteria (IBP handbook no. 15). Oxford: Blackwell Scientific Publications.

Ward, M. J., Harrison, D. M., Ebner, M. J. \& Armitage, J. P. (1995).
Identification of a methyl-accepting chemotaxis protein in Rhodobacter sphaeroides. Mol Microbiol 18, 115-121.

Zhang, W., Brooun, A., McCandless, J., Banda, P. \& Alam, M. (1996). Signal transduction in the Archaeon Halobacterium salinarium is processed through three subfamilies of 13 soluble and membrane-bound transducer proteins. Proc Natl Acad Sci USA 93, 4649-4654.

Zuberi, A. R., Ying, C. W., Parker, H. M. \& Ordal, G. W. (1990). Transposon Tn917lacZ mutagenesis of Bacillus subtilis: identification of two new loci required for motility and chemotaxis. J Bacteriol 172, 6841-6848.

Received 22 December 1997; revised 6 March 1998; accepted 16 March 1998. 